\title{
Capacity Index System Research of Software Engineering Major based on TOPCARES-CDIO
}

\author{
Zhang Chong ${ }^{1, a,{ }^{*}}$, Yan Debiao ${ }^{2, b}$ and Zhong Baocai ${ }^{3, c}$ \\ ${ }^{1}$ Chengdu Neusoft University, Chengdu, China \\ ${ }^{2}$ Chengdu Neusoft University, Chengdu, China \\ ${ }^{3}$ Chengdu Neusoft University, Chengdu, China \\ azhangchong@nsu.edu.cn, bYandebiao@nsu.edu.cn, 'chongbaocai@nsu.edu.cn \\ *Zhangchong, Chengdu Neusoft University, Chengdu, China
}

Keywords: CDIO, Software Engineering, Capacity Index.

\begin{abstract}
CDIO educational pattern is the latest achievement of the international engineering education reform. This paper obtains the capacity index system of software engineering major based on TOPCARES-CDIO ( T-C) education idea according to the latest industry research. This system can be a very detail foundation for the personnel training program and course schedule making.
\end{abstract}

\section{基于TOPCARES-CDI0的软件工程专业人才培养能力指标体系研究 \\ 张羽 $1,{ }^{a},{ }^{*}$ ，颜德彪 $2, b$ ，仲宝才 ${ }^{3, c}$ \\ 1成都东软学院信息与软件工程系，成都，中国 \\ 2成都东软学院信息与软件工程系, 成都, 中国 \\ 3成都东软学院信息与软件工程系，成都，中国 \\ azhangchong@nsu.edu.cn, bYandebiao@nsu.edu.cn, 'chongbaocai@nsu.edu.cn \\ *中国四川省成都市都江堰青城山镇成都东软学院 张羽}

关键词: CDIO, 软件工程, 能力指标

中文摘要. CDIO工程教育模式是近年来国际工程教育改革的最新成果,本文以具有中国特色的 TOPCARES-CDIO (简称T-C) 为基本教育理念, 根据软件行业的最新调研结果, 推导出软件 工程专业在人才培养方面应具备的能力指标体系，从而为软件工程专业人才培养方案和课程 体系的制订提供了详实的依据。

\section{1. 引言}

CDIO工程教育模式是近年来国际工程教育改革的最新成果，它是麻省理工学院和瑞典皇 家工学院等四所大学组成的跨国研究机构于 2000年提出的工程教育理念。CDIO代表构思 (Conceive) 、设计（Design）、实现（Implement）和运作（Operate）,它以产品研发到产品 运行的生命周期为载体，让学生以主动的、实践的、课程之间有机联系的方式学习工程。CDIO 的理念不仅继承和发展了欧美20多年来工程教育改革的理念，更重要的是系统地提出了具有 可操作性的能力培养、全面实施以及检验测评的 12 条标准 ${ }^{1}$ 。 
大连东软信息学院基于 “教育创造学生价值”的理念，借鉴CDIO工程教育模式、在继承 CDIO的基础上, 创造性地将CDIO中国化和本地化, 在充分考虑学生、教师、产业和社会等利 益相关者的需求基础上, 结合中国高等教育的实际和IT行业的人才需求标准, 针对学院IT专 业的设置情况, 对 CDIO能力培养大纲做了继承基础上的创新, 构建了具有东软特色的 “TOPCARES-CDIO”2八大能力指标体系。

“TOPCARES-CDIO” ( 以下简称T-C) 作为大连东软信息学院人才能力培养的基本理念, 其每一个字母代表学生应当具备的一种能力, 具体是指, $\mathrm{T}$ ( Technical Knowledge and Reasoning) 技术知识与推理能力, $\mathrm{O}$ (Open Minded and Innovation) 开放式思维与创新, P(Personal and Professional Skills) 个人职业能力, C (Communication and Teamwork) 沟通表达与团队工作, A (Attitude and Manner) 态度与习惯, R（Responsibility）责任感，E（Ethical Values）价值 观, S (Social Value Created by Application Practice) 实践应用创造社会价值 ${ }^{3}$ 。该能力指标体 系由 8 个一级指标， 34 个二级指标和 126 个三级指标组成。

成都东软学院从2010年就开始实施了T-C教学改革, 实施 “面向职业岗位的课程体系设计 的反向推导流程” ，即根据市场对 IT人才的能力结构需求推导出专业的能力指标体系，从而 作为人才培养方案及课程体系制订的依据。

\section{2. 调研过程}

下面以成都东软学院的王牌专业-软件工程专业为例来说明人才培养能力指标体系的构 建过程，该过程共分五步完成。

第一步 相关专业、行业调研与分析。

我们首先对IT行业，尤其是软件开发行业的国际、国内、区域发展现状和未来发展趋势 进行了调研, 通过分析国家、部门、行业发展现状及对专业人才的需求等, 形成了软件开发 行业分析报告。由此我们得到的结论是：软件业不仅是全球整个信息通信技术产业中增长最 快速的产业，也是创新最活跃的行业。我国的软件和信息技术服务业目前有近 600 万从业人 员, 在云计算、移动互联网、大数据、虚拟现实、人工智能等新技术驱动下，软件正以跨界 融合的面貌出现在世人面前。而软件工程作为计算机领域发展最快的学科分支之一, 得到了 国家的高度重视。在所有软件开发类人才的需求中对Java工程师的需求达到全部需求量的 60 70\%。成都作为成渝经济区的代表, 其信息服务业和软件业始终保持着快速发展的势 头。

\section{第二步 行业岗位分析。}

这里主要是通过行业岗位群的描述对岗位能力进行结构分析。我们通过著名的智联招聘 网站搜索到软件工程师相关的职位共55188个，其中成都6357个，北京23147个，上海13699 个, 深圳7903个, 西安4082个。随后, 我们从这些企业中选择了有代表性的50家企业进行了 调研, 我们对企业招聘中所提到的技术知识细节进行了详细的统计, 如下:

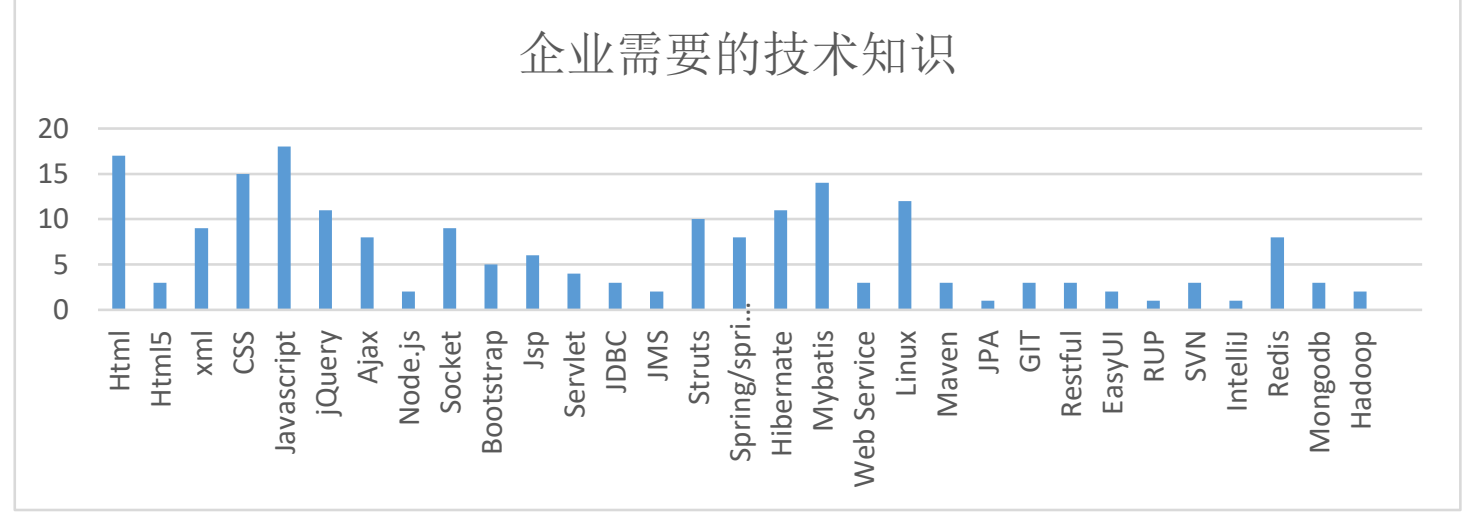

图1 企业招聘中需要的技术知识 
从上图可以看到, 以 Html, Javascript ,css 为代表的网页开发技术需求量依旧很大。在Java 开源框架方面, Struts,Spring,Mybatis,Hibernate依然是主流, 但Mybatis已赶超Hibernate。另外, Linux下的编程, 以Redis为代表的云存储技术, Socket编程, 以及jQuery等技术都越来越受到 企业的青睐。

我们对企业的软素质需求方面也进行了分析，如下：

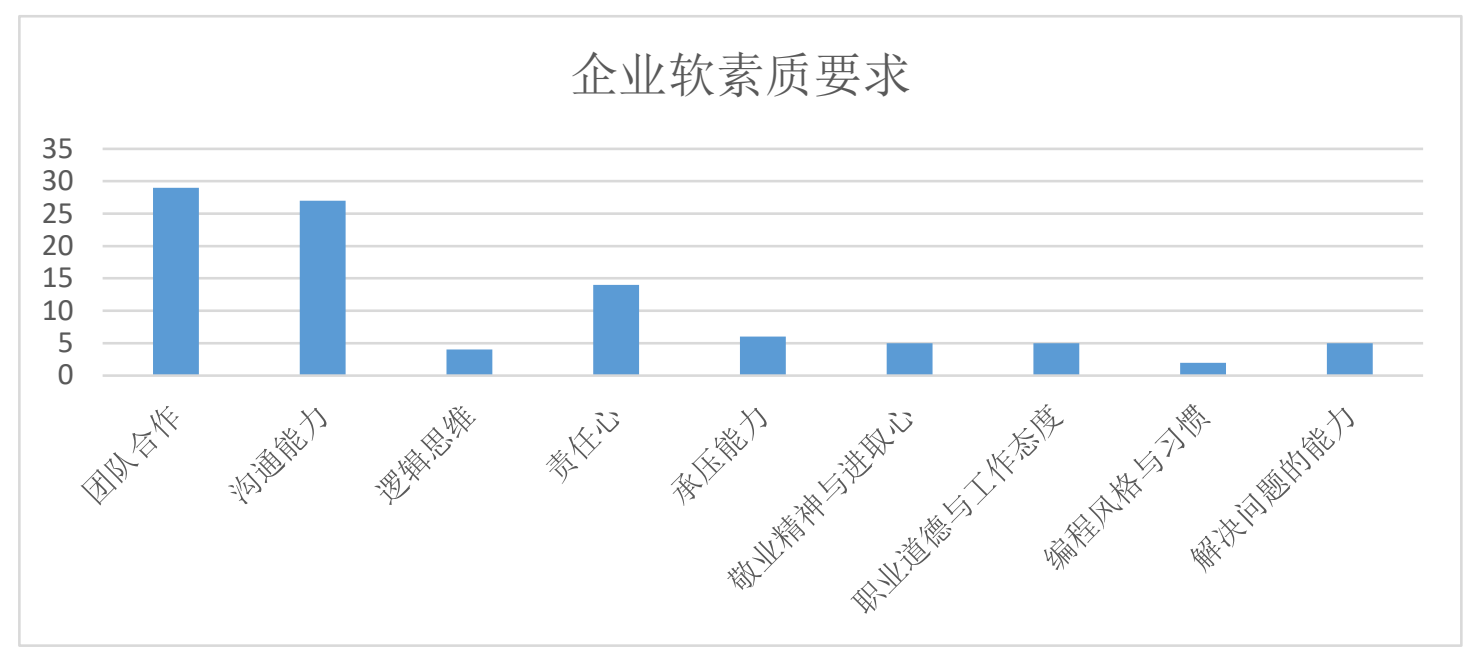

图2 企业对应聘人员的软素质要求

可以看到，企业最看重的求职人员的软素质分别是团队合作，沟通能力和责任心。 然后我们又对岗位能力进行了分析, 如下:

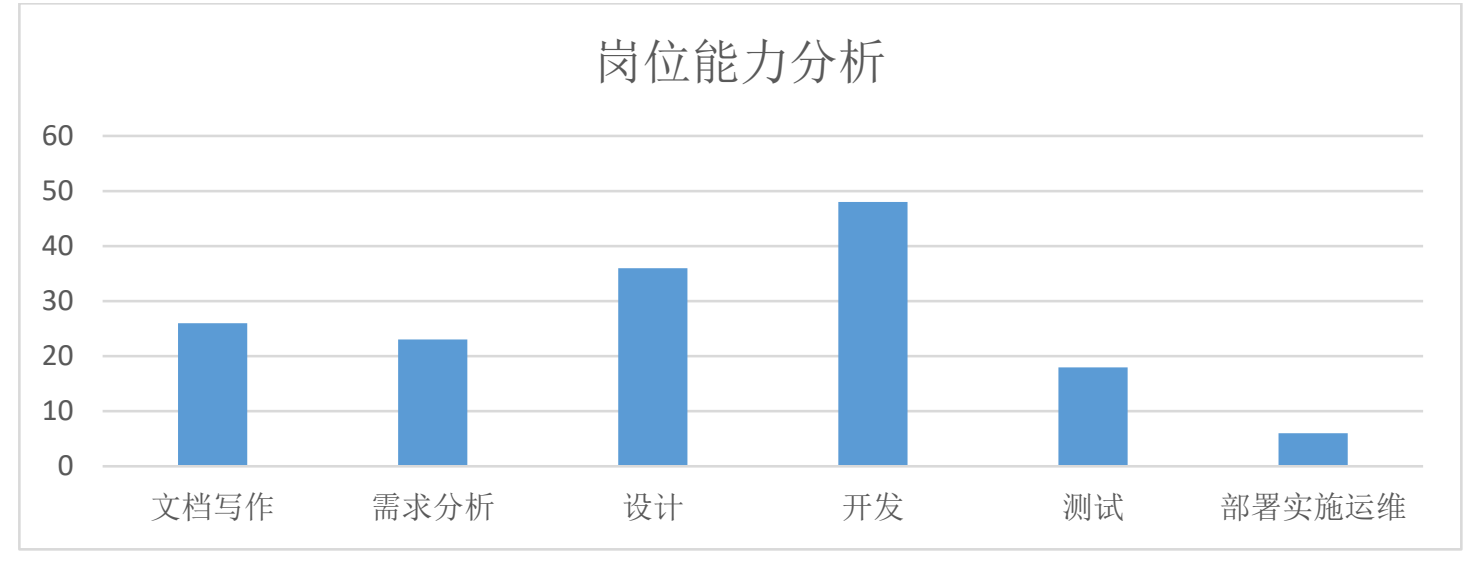

图3 企业的岗位能力需求

可以看到企业最看重员工的编码能力, 其次是系统设计及文档写作能力。

以上只是我们对企业人才招聘要求分析统计的一个缩影, 实际上我们根据 $\mathrm{T}-\mathrm{C}$ 的能力指标 体系, 设计了更为精细的调查问卷以及更详细的能力分类分析, 从而能够获得企业对人才更 全面的需求信息。

第三步: 人才培养定位对比分析。

我们选取了国内外以麻省理工大学、斯坦福大学、清华大学、南京大学等为代表的部分 院校软件工程相关专业, 详细分析了这些专业的人才培养目标及毕业标准, 从而了解到主流 大学对软件工程专业人才培养能力要求的总体趋势。

第四步：课程设置对比分析。

随后，我们又详细分析了国内、外典型大学、培训机构相关专业课程设置状况，对专业 课、核心课等的课程目标、课程内容的基本要求等方面进行了对比分析，从而了解到各类大 学、教育机构对软件工程专业人才培养方面更细节的能力和知识要求。

第五步：确定人才培养定位。 
根据以上的调研结果, 我们结合高等学校本科软件工程专业规范, 最终确定软件工程专 业的培养目标为: 培养具有扎实的现代软件工程基本理论, 掌握通用软件及移动应用软件的 分析、设计和开发方法，熟悉主流软件开发平台、工具和软件开发技术，具有较强的软件开 发实践能力、技术创新能力和创业意识, 具有较强的外语应用能力和团队协作能力, 具有国 际化视野和社会责任感，能适应技术进步、社会需求变化和区域经济发展的高素质软件工程 专门人才 ${ }^{4}$ 。

\section{3. 结论}

根据以上的行业企业, 国内外高校专业课程体系的调研结果, 我们在T-C及CDIO能力指 标体系的基础之上，推导出软件工程专业的人才培养能力指标体系 ${ }^{5}$ 如下:

表1: 《软件工程》专业人才培养核心能力指标

\begin{tabular}{|c|c|c|c|}
\hline $\begin{array}{l}\text { TOPCARES (1 } \\
\text { 级能力指标) }\end{array}$ & $\begin{array}{l}\text { TOPCARES (2 } \\
\text { 级能力指标) }\end{array}$ & $\begin{array}{l}\text { TOPCARES（3级能力指 } \\
\text { 标） }\end{array}$ & 核心能力指标说明 \\
\hline \multirow{5}{*}{$\begin{array}{c}1 \text { Technical } \\
\text { knowledge and } \\
\text { reasoning } \\
\text { 技术知识与推理 } \\
\text { 能力 }\end{array}$} & \multirow{3}{*}{$\begin{array}{c}1.1 \text { 相关科学知 } \\
\text { 识 }\end{array}$} & 1.1.1人文社会科学知识 & 心理学, 思想道德, 法律等 \\
\hline & & 1.1.2自然科学知识 & 数学, 物理等学科知识 \\
\hline & & 1.1 .3 外语知识 & 英语相关知识 \\
\hline & $\begin{array}{l}1.2 \text { 专业基础知 } \\
\text { 识 }\end{array}$ & 1.2.1专业基础知识 & 软件开发相关专业基础知识 \\
\hline & 1.3 专业知识 & 1.3 .1 专业知识 & 软件开发相关专业知识 \\
\hline \multirow{9}{*}{$\begin{array}{l}2 \text { Open thinking } \\
\text { and innovation } \\
\text { 开放式思维与创 } \\
\text { 新 }\end{array}$} & \multirow{3}{*}{2.1 系统思维 } & 2.1.1全方位思维 & $\begin{array}{l}\text { 识别并定义一个系统、系统行为和系统单元, 识别系统与外 } \\
\text { 界的交互作用和对系统行为的影响 }\end{array}$ \\
\hline & & 2.1.2系统的显现和交互作用 & $\begin{array}{l}\text { 讨论为定义系统和系统建模所需的抽象化, 识别系统所表现 } \\
\text { 的行为和功能特性 (意向中和意向外的), 识别系统单元间 } \\
\text { 的重要接口 }\end{array}$ \\
\hline & & 2.1.3确定主次与重点 & 找出并区分与系统整体相关的全部因素 \\
\hline & \multirow[b]{2}{*}{2.2 批判性思维 } & 2.2.1分析问题 & 分析系统所要解决的问题 \\
\hline & & $\begin{array}{l}\text { 2.2.4找出有矛盾的观点、理 } \\
\text { 论和事实 }\end{array}$ & 能找出问题中存在的矛盾 \\
\hline & 2.3 创造性思维 & $\begin{array}{c}\text { 2.3.1具有概念化和抽象化能 } \\
\text { 力 }\end{array}$ & 识别项目功能、对象并进行抽象 \\
\hline & \multirow{3}{*}{2.4 创新能力 } & $\begin{array}{c}\text { 2.4.1引进、消化、吸收再创 } \\
\text { 新能力 } \\
\end{array}$ & $\begin{array}{l}\text { 针对具体的应用和实际的问题, 能够运用所学知识对问题进 } \\
\text { 行抽象, 提取它的逻辑结构和存储结构。 }\end{array}$ \\
\hline & & 2.4.2集成创新能力 & $\begin{array}{l}\text { 知识集成（个体知识到群体知识）, 技术集成（单项技术或 } \\
\text { 系统到多项技术或系统的集成） }\end{array}$ \\
\hline & & 2.4.3原始创新能力 & 创新研究方法, 重视交叉学科上的创新研究 \\
\hline \multirow{10}{*}{$\begin{array}{l}3 \text { Personal and } \\
\text { professional } \\
\text { skills } \\
\text { 个人职业能力 }\end{array}$} & \multirow{4}{*}{$\begin{array}{l}3.1 \text { 推理和解决 } \\
\text { 问题的能力 }\end{array}$} & 3.1.1发现问题和表述问题 & 把握总体目标、分清事情的主次, 制定解决方案 \\
\hline & & 3.1.2建模 & $\begin{array}{l}\text { UML建模, 应用假设简化复杂的系统和环境, 选择并应用 } \\
\text { 概念性和定性模型 }\end{array}$ \\
\hline & & 3.1.3估计与定性分析 & 估计量级、范围、趋势 \\
\hline & & 3.1.5解决方法和建议 & 综合问题的解决方案, 分析解决方案的关键结果和测试数据 \\
\hline & \multirow{2}{*}{$\begin{array}{c}3.2 \text { 实验和发现 } \\
\text { 知识 }\end{array}$} & $\begin{array}{c}\text { 3.2.2查询印刷资料和电子文 } \\
\text { 献 }\end{array}$ & $\begin{array}{l}\text { 应用图书馆工具 (在线检索、数据库、搜索引擎等) 检索并 } \\
\text { 获取信息, 主要信息的整理与分类, 提取信息中重点和创新 } \\
\text { 的内容 }\end{array}$ \\
\hline & & 3.2.3实验性的探索 & $\begin{array}{l}\text { 构建课程实验, 执行实验规定和实验步骤, 执行实验测量, } \\
\text { 分析和报告实验数据, 形成总结性建议 }\end{array}$ \\
\hline & \multirow{2}{*}{$\begin{array}{c}3.3 \text { 信息处理能 } \\
\text { 力 }\end{array}$} & 3.3.1基本信息处理能力 & $\begin{array}{l}\text { 文档处理能力（文字录入、word、ppt、excel），获取信息 } \\
\text { 能力 }\end{array}$ \\
\hline & & 3.3.2信息再加工能力 & 评价信息能力, 整合信息能力 \\
\hline & $\begin{array}{l}3.4 \text { 时间和资源 } \\
\text { 的管理能力 }\end{array}$ & 3.4.1讨论任务安排的主次 & 能有效的分清任务的主次 \\
\hline & $\begin{array}{c}3.5 \text { 终身学习能 } \\
\text { 力 }\end{array}$ & 3.5.1职涯规划 & 讨论个人职业发展的愿景, 认识自己所具备的职业能力范畴 \\
\hline \multirow{2}{*}{$\begin{array}{c}4 \\
\text { Communication } \\
\text { and teamwork }\end{array}$} & \multirow{2}{*}{4.1 交流能力 } & 4.1.3书面的交流 & $\begin{array}{l}\text { 展示文章内容的连贯性和流畅性, 展示技术写作能力, 正确 } \\
\text { 的拼写、标点符号和语法写作。 }\end{array}$ \\
\hline & & 4.1.4电子及多媒体交流 & $\begin{array}{l}\text { 能制作电子演示材料, 应用各种电子表达形式（图形、网页 } \\
\text { 等） }\end{array}$ \\
\hline
\end{tabular}




\begin{tabular}{|c|c|c|c|}
\hline \multirow[t]{7}{*}{$\begin{array}{l}\text { 沟通表达与团队 } \\
\text { 合作 }\end{array}$} & & 4.1.5 图表交流 & $\begin{array}{l}\text { 能画草图和正式图纸；制作表图；解释正式技术图纸和图像 } \\
\text { 效果。 }\end{array}$ \\
\hline & & 4.1.6口头表达和人际交流 & $\begin{array}{l}\text { 能够使用适当的语言、风格、时间和流程准备报告和相应的 } \\
\text { 支撑媒介, 能有效回答问题 }\end{array}$ \\
\hline & \multirow{2}{*}{$\begin{array}{c}\text { 4.2使用外语能 } \\
\text { 力 }\end{array}$} & 4.2.1基本的听说读写 & 英语基本的听说读写能力 \\
\hline & & $\begin{array}{c}\text { 4.2.2阅读、理解专业领域文 } \\
\text { 献 } \\
\end{array}$ & 查阅Java API文档的能力 \\
\hline & \multirow{3}{*}{4.3 团队工作 } & 4.3.1组建有效的团队 & $\begin{array}{l}\text { 以小组为单位开展教学, 明确任务和团队工作过程, 分清团 } \\
\text { 队的作用与责任 }\end{array}$ \\
\hline & & 4.3.2团队工作运行 & $\begin{array}{l}\text { 实施计划和组织有效会议, 实施有效交流（聆听、合作、提 } \\
\text { 供和接受信息）, 进行正面和有效的反馈, 实现项目的规 } \\
\text { 划、安排和执行, 形成问题的解决方案 }\end{array}$ \\
\hline & & 4.3.3团队成长和演变 & $\begin{array}{l}\text { 讨论阶段性小结、评估和自评的策略, 认识保障团队运行和 } \\
\text { 成长的技巧, 解释团队交流和写作策略 }\end{array}$ \\
\hline \multirow{3}{*}{$\begin{array}{l}5 \text { Attitude and } \\
\text { manner } \\
\text { 态度与习惯 }\end{array}$} & $\begin{array}{l}5.1 \text { 个体性态度 } \\
\text { 与习惯 }\end{array}$ & 5.1.2学习态度与习惯 & 项目开发中的学习态度与习惯 \\
\hline & \multirow{2}{*}{$\begin{array}{l}5.2 \text { 职业态度与 } \\
\text { 习惯 }\end{array}$} & $\begin{array}{l}\text { 5.2.1敬业 (自信、有激情、 } \\
\text { 热爱事业) }\end{array}$ & 有敬业精神 \\
\hline & & 5.2.3实事求是 & 在工作中实事求是 \\
\hline \multirow{9}{*}{$\begin{array}{l}6 \text { Responsibility } \\
\text { 责任感 }\end{array}$} & \multirow{3}{*}{$\begin{array}{l}6.1 \text { 对自我的责 } \\
\text { 任感 }\end{array}$} & 6.1.1对自己生命的责任 & 珍爱自己的生命 \\
\hline & & 6.1.2对自身健康的责任 & 珍惜自己的身体健康 \\
\hline & & 6.1.3对自我价值实现的责任 & 在项目开发中体现自我价值 \\
\hline & \multirow{2}{*}{$\begin{array}{c}6.2 \text { 对他人的责 } \\
\text { 任感 }\end{array}$} & 6.2.1对家庭的责任 & 承担自己在家庭中的责任 \\
\hline & & 6.2 .2 对他人的责任 & 承担项目中对他人的责任 \\
\hline & \multirow{2}{*}{$\begin{array}{l}6.3 \text { 对职业的责 } \\
\text { 任感 }\end{array}$} & $\begin{array}{l}\text { 6.3.1职业道德、正直并勇于 } \\
\text { 负责 }\end{array}$ & 具有职业道德 \\
\hline & & 6.3.2职业行为 & 能区分职责 \\
\hline & \multirow{2}{*}{$\begin{array}{c}6.4 \text { 对社会的责 } \\
\text { 任感 } \\
\end{array}$} & 6.4.1社会公德 & 具有社会公德 \\
\hline & & 6.4.2遵纪守法 & 在日常生活中遵纪守法 \\
\hline \multirow{5}{*}{$\begin{array}{l}7 \text { Ethical values } \\
\text { 价值观 }\end{array}$} & 7.1 个人价值观 & 7.1.1追求知识与真理 & 有浓厚的学习兴趣 \\
\hline & 7.2 职业价值观 & 7.2 .3 个人与团队共同成长 & 项目开发中的团队与个人关系处理 \\
\hline & \multirow{3}{*}{7.3 社会价值观 } & $\begin{array}{l}\text { 7.3.1坚持马克思主义指导思 } \\
\text { 想 } \\
\end{array}$ & 学习并信仰马克思主义 \\
\hline & & $\begin{array}{c}7.3 .2 \text { 坚持中国特色社会主义 } \\
\text { 共同理想 } \\
\end{array}$ & 学习并信仰中国特色社会主义 \\
\hline & & $\begin{array}{l}\text { 7.3.3坚持以爱国主义为核心 } \\
\text { 的民族精神和以改革创新为 } \\
\quad \text { 核心的时代精神 }\end{array}$ & 具有爱国主义和民族自豪感 \\
\hline \multirow{10}{*}{$\begin{array}{c}8 \text { Social } \\
\text { contribution by } \\
\text { application } \\
\text { practice } \\
\text { (CDIO) } \\
\text { 实践构思、设 } \\
\text { 计、实现和运行 } \\
\text { 为社会的贡献 }\end{array}$} & \multirow{2}{*}{$\begin{array}{l}8.1 \text { 外部和社会 } \\
\text { 背景环境 }\end{array}$} & 8.1.1工程师的角色与责任 & 接受工程职业的目标和角色, 接受工程师的社会责任 \\
\hline & & 8.1.2工程对社会的影响 & $\begin{array}{l}\text { 解释工程对现代文化下环境、社会、知识以及经济体系的影 } \\
\text { 响 }\end{array}$ \\
\hline & \multirow{2}{*}{$\begin{array}{l}8.2 \text { 创业技能 } \\
\text { (创业过程和特 } \\
\text { 征、与创业过程 } \\
\text { 相关的行为) }\end{array}$} & 8.2 .1 发现过程 & $\begin{array}{l}\text { 评估创业机会、描述创意产生的方法、产生创意、确定创意 } \\
\text { 的可行性 }\end{array}$ \\
\hline & & 8.2.4付诸实践过程 & $\begin{array}{l}\text { 运用外部资源补充创业者的专门知识、评价风险机会、描述 } \\
\text { 经营程序的使用 }\end{array}$ \\
\hline & \multirow{2}{*}{$\begin{array}{l}8.3 \text { 基本商业知 } \\
\text { 识与技能 }\end{array}$} & $\begin{array}{l}\text { 8.3.1商业基础（了解影响商 } \\
\text { 业决策的基本商业观念） }\end{array}$ & 商业观念、商业活动 \\
\hline & & $\begin{array}{l}8.3 .2 \text { 经济学基础 (了解创业 } \\
\text { /小企业所有权的经济原则 } \\
\text { 和基本概念) }\end{array}$ & 基础概念、成本利益关系、国际观念 \\
\hline & \multirow[b]{2}{*}{ 8.4商业技能 } & 8.4.1财务管理 & 会计学、金融学、理财能力 \\
\hline & & 8.4 .2 人力资源管理 & 组织员工、配置员工、培训发展员工、激励员工、评估员工 \\
\hline & \multirow[b]{2}{*}{$\begin{array}{l}8.5 \text { 行业应用环 } \\
\text { 境 }\end{array}$} & 8.5.1行业基本规范 & 代码、图表、文档符合软件工程规范 \\
\hline & & 8.5.2行业应用技术 & $\begin{array}{l}\text { Htm15,JavaScript,JSP,Servlet,Java,Struts,Spring,Hibernate等行 } \\
\text { 业技术的应用 }\end{array}$ \\
\hline
\end{tabular}




\begin{tabular}{|c|c|c|}
\hline \multirow{4}{*}{$\begin{array}{l}8.6 \text { 系统的构思 } \\
\text { 与工程化 }\end{array}$} & 8.6.1设立系统目标和要求 & $\begin{array}{l}\text { 找出并分析顾客需求、解释系统目标和要求、识别表示目标 } \\
\text { 和要求的语言/形式、解释初期目标 (基于需求、机会和其 } \\
\text { 他影响)、解释系统性能指标 }\end{array}$ \\
\hline & 8.6.2定义功能, 概念和结构 & $\begin{array}{l}\text { 确定必要的系统功能 (以及系统的行为指标), 区分高层次 } \\
\text { 的构架形式和结构, 讨论将构架形式分解为单元, 给单元赋 } \\
\text { 予功能并定义单元间的接口 }\end{array}$ \\
\hline & $\begin{array}{c}\text { 8.6.3系统建模和确保目标实 } \\
\text { 现 }\end{array}$ & $\begin{array}{l}\text { 找出技术性能指标的合理模型, 讨论实施和运行的概念, 讨 } \\
\text { 论各种目标、功能、概念和结构间的取舍以及收玫所需的迭 } \\
\text { 代 }\end{array}$ \\
\hline & 8.6.4开发项目的管理 & $\begin{array}{l}\text { 解释配置管理和文档, 讨论资源的估算和分配, 描述发展的 } \\
\text { 过程可能的改进 }\end{array}$ \\
\hline \multirow{4}{*}{8.7 设计 } & 8.7.1 设计过程 & $\begin{array}{l}\text { 为系统目标和要求导出的每个单元或元件选择要求, 在约束 } \\
\text { 条件下实施适合的优化, 进行迭代直至收玫, 综合最终设 } \\
\text { 计, 能适应需求的变化 }\end{array}$ \\
\hline & 8.7.2设计过程的分段与方法 & $\begin{array}{l}\text { 讨论适应特定开发项目的过程模型（自上而下模式、螺旋模 } \\
\text { 式、并行模式等） }\end{array}$ \\
\hline & 8.7.3知识在设计中的利用 & $\begin{array}{l}\text { 实践创造性和批判性思维并解决问题, 利用技术和科学知 } \\
\text { 识, 实践创造性和批判性思维并解决问题 }\end{array}$ \\
\hline & 8.7.4单学科设计 & $\begin{array}{l}\text { 选择合适的技术、工具和过程, 实施建模、模拟和测试, 讨 } \\
\text { 论设计的分析改进 }\end{array}$ \\
\hline \multirow[t]{2}{*}{8.8 实施 } & 8.8.3软件实现过程 & $\begin{array}{l}\text { 解释将高层组成部分分解为模块设计 (包括算法和数据结 } \\
\text { 构), 讨论算法 (数据结构、控制流程、数据流程) , 描述 } \\
\text { 编程语言, 描述系统构建 }\end{array}$ \\
\hline & $\begin{array}{c}8.8 .5 \text { 测试、证实、验证及认 } \\
\text { 证 }\end{array}$ & $\begin{array}{l}\text { 讨论测试和分析的程序, 讨论证实系统性能达到要求, 讨论 } \\
\text { 验证性能达到客户要求 }\end{array}$ \\
\hline 8.9运行 & 8.9.1运行的设计和优化 & 解释运行过程的架构和发展 \\
\hline
\end{tabular}

以上推导出的软件工程专业三级 T-C能力指标体系，具有 8 个一级指标， 34 个二级指标和 55 个三级指标, 是根据以上的五步调研过程的分析结果, 从原始的 T-C及CDIO指标中提炼出 来的。可以看到, 推导出的能力指标体系覆盖了全部的T-C和CDIO的一级和二级指标, 与CDIO 工程教育的要求相吻合。目前, 该能力指标体系已作为软件工程专业人才培养方案制订和课 程体系设置的依据, 并应用到成都东软学院中, 随后我们将这些能力指标逐个映射到每门课 程中，制订出软件工程专业的课程体系，取得了良好的效果。

\section{References}

[1] Gupeihua,Shenminfen, Rethinking Engineering Education, Beijing higher education press, pp. 30-32, 2009.

[2] Wentao, Integrated Talent Training Pattern Research and Practice based on TOPCARES-CDIO, Computer Education, vol.11, pp. 23-25, 2010.

[3] Dongwenliang,Guoquan,Liuhui, Sample Analysis of the Talent Training Target System building of the Applied Technology University: Take the building of TOPCARES-CDIO Capacity index system as example, Modern Education Management, vol.8, pp. 100-104, 2015.

[4] Software Engineering Major Teaching Guidance Committee of Education Ministration, Software Engineering Major Specification, Beijing higher education press, pp. 7-8, 2011.

[5] Kouyouzhi, Major Talent Training Program Design and Implementation based on TOPCARESCDIO, Education and Teaching Forum, vol. 86, pp. 1-10, 2003. 